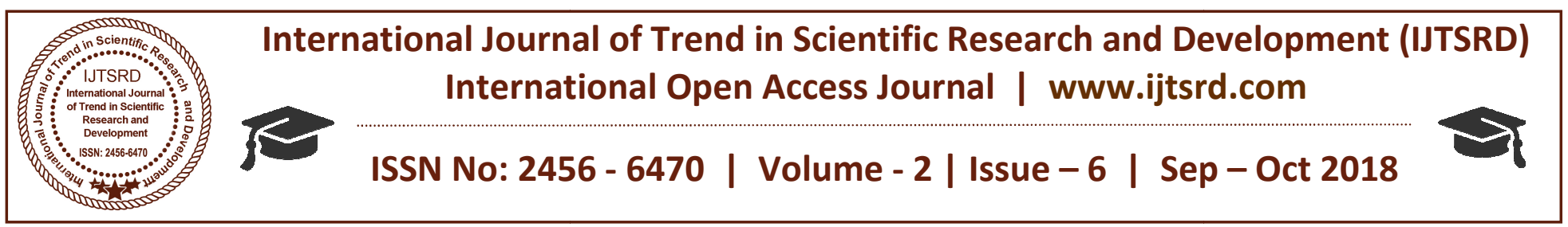

\title{
Experimental Analysis of Corrosion Resistance on Columnar to Equiaxed Transition Region of as Cast Structures of AL-CU Alloys
}

\author{
Ganesan Venkatachalam
}

Lecturer (Senior Grade)/Chemistry, Nachimuthu Polytechnic College, Pollachi, Tamil Nadu, India

\begin{abstract}
In the present article, in order to investigate the corrosion resistance tendency on both sides of the columnar to equiaxed transition (CET), some samples of $\mathrm{Al}-\mathrm{Cu}$ alloys (5 and $8 \mathrm{wt}-\% \mathrm{Cu}$ ) were prepared on the columnar and on the equiaxed sides of the casting and subjected to corrosion tests. The corrosion resistance has been analysed by both the electrochemical impedance spectroscopy technique and Tafel extrapolation method conducted in a $3 \% \mathrm{NaCl}$ solution at room temperature. It was found that both columnar and equiaxed morphologies at the CET region, for each alloy examined, have attained similar experimental electrochemical impedance and polarisation results. The secondary dendrite arm spacings 12 on both columnar and equiaxed sides of the CET region are very similar in any case experimentally examined and the resemblance on the corrosion resistance of columnar and equiaxed structures has been attributed to the similarity of such micro structural parameter.
\end{abstract}

Keyword: Columnar to equiaxed transition, Dendrite arm spacing, Corrosion resistance

\section{INTRODUCTION}

It is well known that the mechanical properties of metallic alloys depend on the as cast structure and that the structural morphology depends on melt properties and on cooling conditions during solidification. Various studies are reported in the literature relating materials yield strength and grain size 1,2 or ultimate tensile strength and primary or secondary dendrite arm spacings.3,4 On the other hand, the as cast structural morphologies (macrostructure and microstructure) may also play an important role in the corrosion behavior of metallic materials. A number of experimental studies have pointed up effects of the structure upon the corrosion resistance by analyzing various structural forms in a number of processes.

Recently, it was reported that pure metals castings have the tendency of corrosion resistance connected only with the macro structural form and grain size owing to the absence of representative micro structural dendrite branches formation. 8 The as cast macrostructure can be mainly represented by chill, columnar and equiaxed regions and can occur in both pure metals and alloys. Equiaxed grains can nucleate and grow ahead of the columnar front provoking an abrupt columnar to equiaxed transition (CET) along a plane parallel to the chill wall.9 However, for alloy castings, micro structural features such as the dendrite arm spacing can be even more important in terms of corrosion resistance than the macro structural morphology. It was found that there are three important factors affecting the corrosion resistance tendency: the cooling rate, the solute redistribution phenomenon and the anodic or cathodic electrochemical behaviour.10 The aim of this study is to investigate the corrosion resistance tendency on both sides of the CET in some important industrial alloys in order to correlate the corrosion behavior with as cast structural features. Al- $\mathrm{Cu}$ alloys samples have been prepared on the columnar and on the equiaxed sides of the casting and were subjected to corrosion tests such as the electrochemical impedance spectroscopy (EIS) technique and Tafel extrapolation method conducted in a $3 \% \mathrm{NaCl}$ solution at room temperature.

\section{EXPERIMENTAL}

Experiments were performed with two different binary hypoeutectic $\mathrm{Al}-\mathrm{Cu}$ alloys (5 and 8 wt-\% $\mathrm{Cu}$ ). A water cooled vertical upward unidirectional 
solidification system was used to obtain the samples of $\mathrm{Al}-\mathrm{Cu}$ alloys. The water cooled system was designed in such a way that the heat was extracted only through the water cooled bottom, promoting upward vertical directional solidification. The used experimental set-up is schematically shown in Fig. 1.

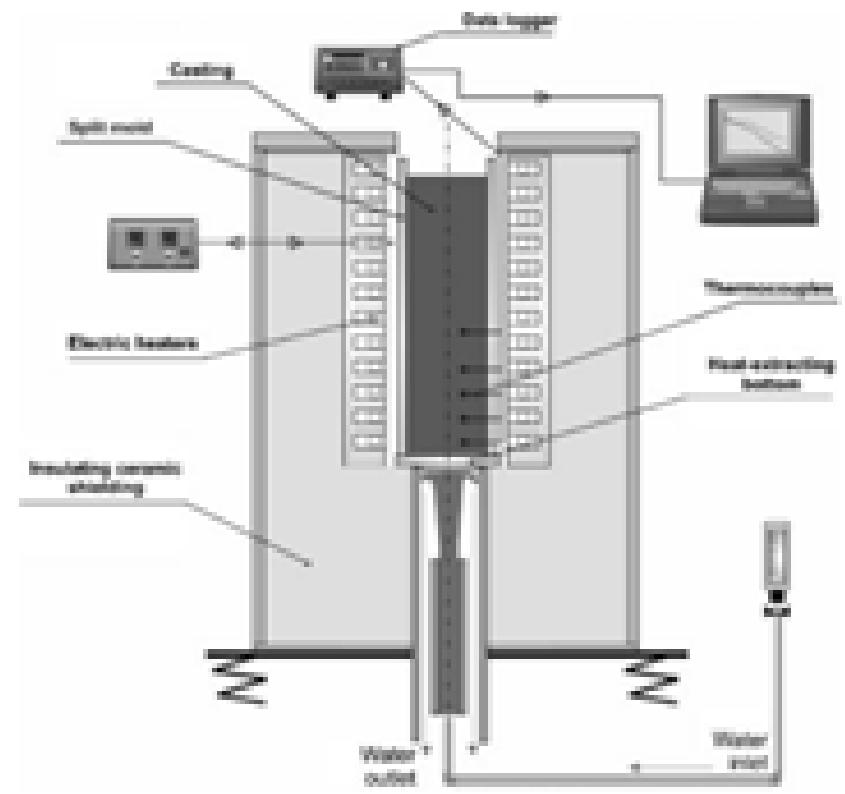

Fig 1 Water cooled vertical upward unidirectional solidification apparatus

Cylindrical as cast specimens were longitudinally sectioned from the centre in order to reveal both the macrostructure and microstructure. An image processing system Neophot 32 and Cambridge Leica500 was used to measure the average dendrite arm spacing at the CET region. Figure 2 shows a schematic representation of the CET region (Fig. 2a) and a table with mean values of secondary dendrite arm spacing 12 measured in both sides of the CET region for each alloy experimentally examined (Fig. $2 b)$.

In order to estimate the tendency of corrosion resistance for the different alloys at the CET region, EIS tests were conducted in a $500 \mathrm{~mL} 3 \% \mathrm{NaCl}$ solution at room temperature. A potentiostat coupled to a frequency analyser system, a glass corrosion cell kit with a platinum counter electrode and a saturated calomel reference electrode (SCE) were used, as prescribed by the ASTM standard G3/89. The working electrodes consisted of as cast alloys samples. The as cast samples were further ground up to a 600 grit $\mathrm{SiC}$ paper, followed by distilled water washing and air drying before each sequence of the EIS and polarisation tests.

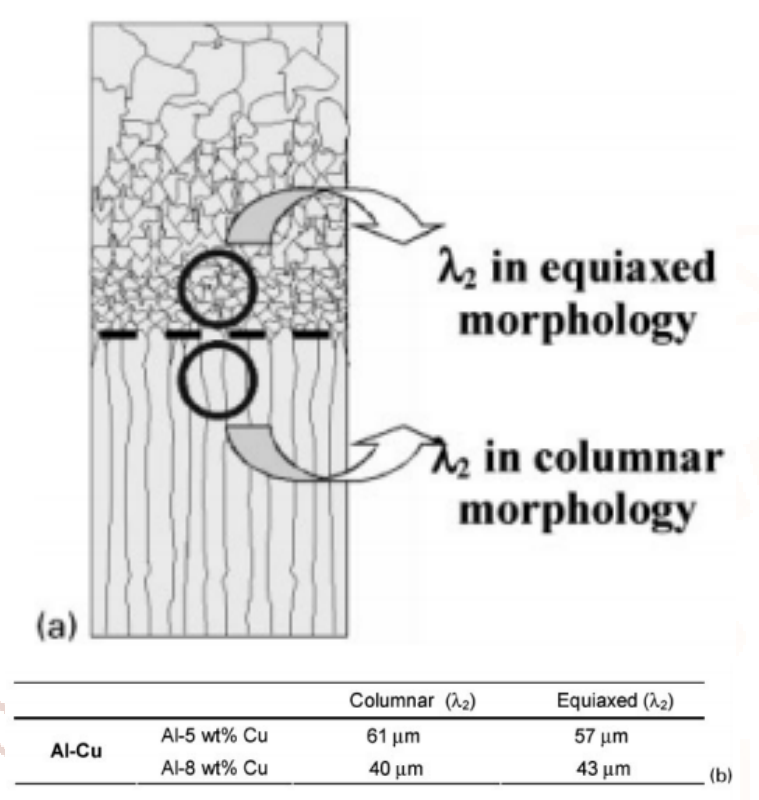

Fig 2 a macrostructure representation at CET and b average values of secondary dendrite arm spacing 12 for $\mathrm{Al}-5 \mathrm{wt}-\% \mathrm{Cu}$ and $\mathrm{Al}-8 \mathrm{wt}-\% \mathrm{Cu}$ alloys

The samples were positioned at the glass corrosion cell kit, leaving a circular $1 \mathrm{~cm} 2$ metal surface in contact with the electrolyte. The potential amplitude was set to $10 \mathrm{mV}$ in open circuit potential and the frequency range was set from $100 \mathrm{mHz}$ to $100 \mathrm{kHz}$. EIS measurements began after an initial delay of 30 min for the sample to reach a steady state condition. Polarisation tests were also conducted in a $500 \mathrm{~mL}$ $3 \% \mathrm{NaCl}$ solution at room temperature using an EG \& G Princeton Applied Research, model 273 A potentiostat. The polarisation tests were conducted by stepping the potential at a scan rate of $0.2 \mathrm{mV} \mathrm{s} 21$ from 2250 (SCE) to $\mathrm{z} 250 \mathrm{mV}$ (SCE) related to open circuit potential. The polarisation curves were plotted, and both corrosion rate and potential were estimated by the Tafel extrapolation method after obtaining triplicate experimental results. All the polarisation tests were performed after each correspondent EIS test.

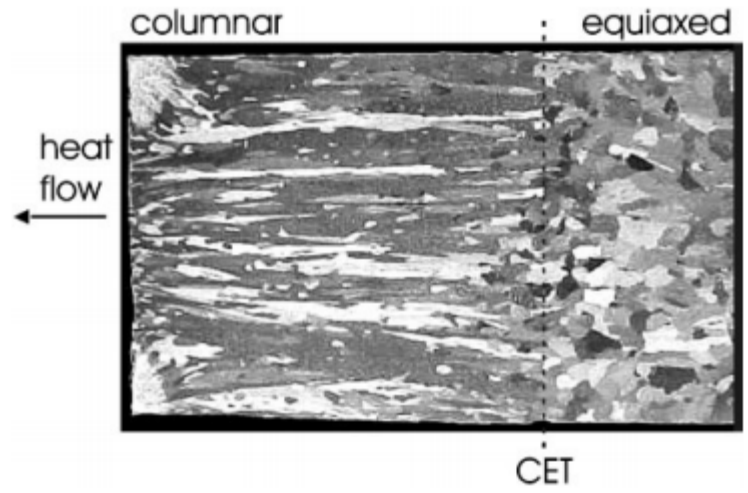

Fig 3 Columnar to equiaxed transition of Al-5 wt$\% \mathrm{Cu}$ directionally solidified sample 


\section{RESULTS AND DISCUSSION}

Figure 3 shows a typical example of the directionally solidified macrostructure of an $\mathrm{Al}-5 \mathrm{wt}-\% \mathrm{Cu}$ alloy. The CET is observed to occur essentially on a near vertical plane and far from the metal/chill interface. The secondary dendrite arm spacing's were measured in both sides of the CET. Figure 4 shows a comparison of experimental results for these two $\mathrm{Al}-$ $\mathrm{Cu}$ alloys concerning EIS diagrams and potentio dynamic polarization curves in both morphologies at the CET vicinity. The EIS experimental results are presented in both Bode and Bode phase representations, as shown in Fig. $4 \mathrm{a}$ and c. In the EIS diagrams shown in Figs. 4a and c, the high frequency limit (f.1 kHz) corresponds to the electrolyte resistance Rel.
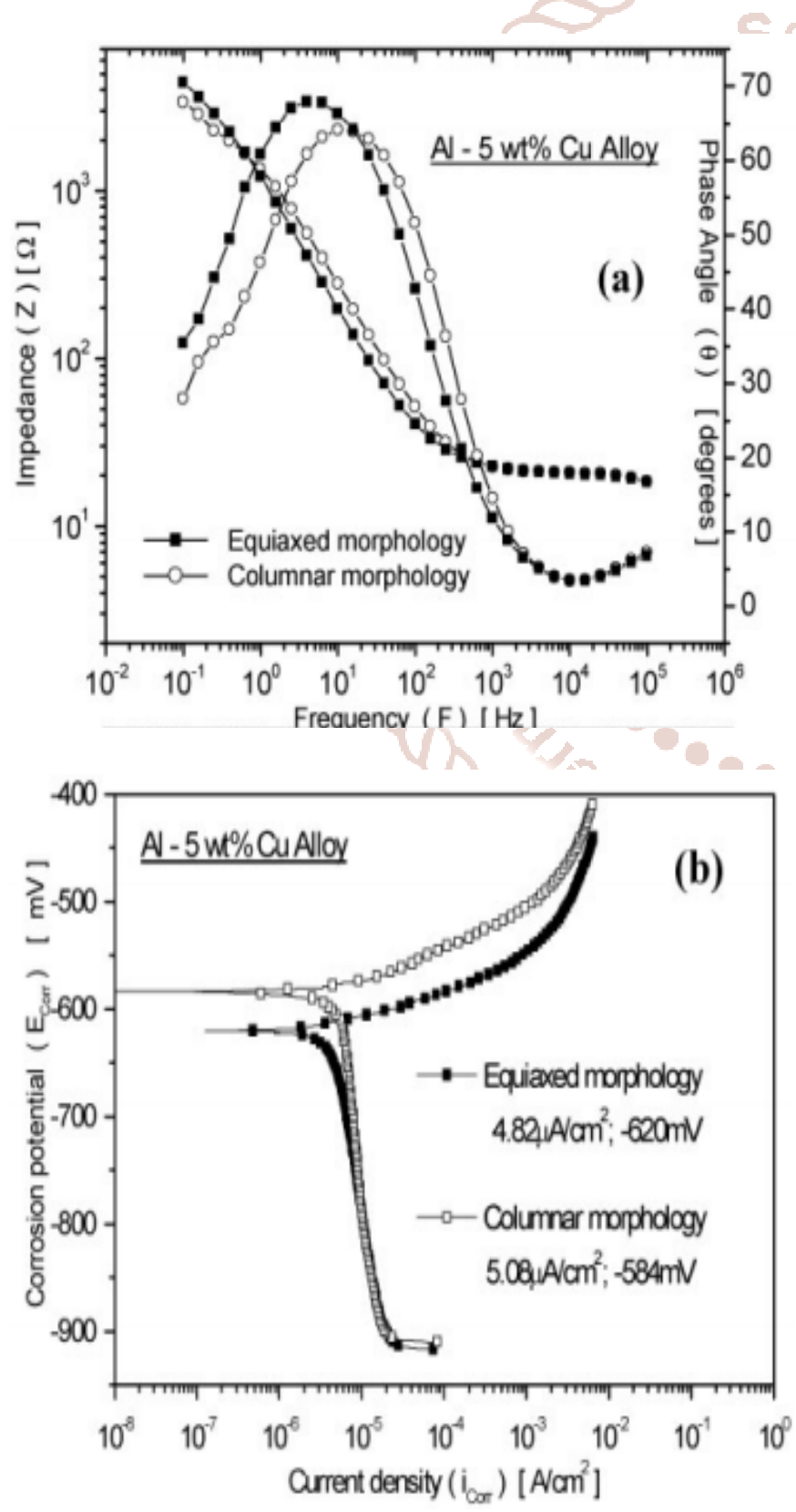
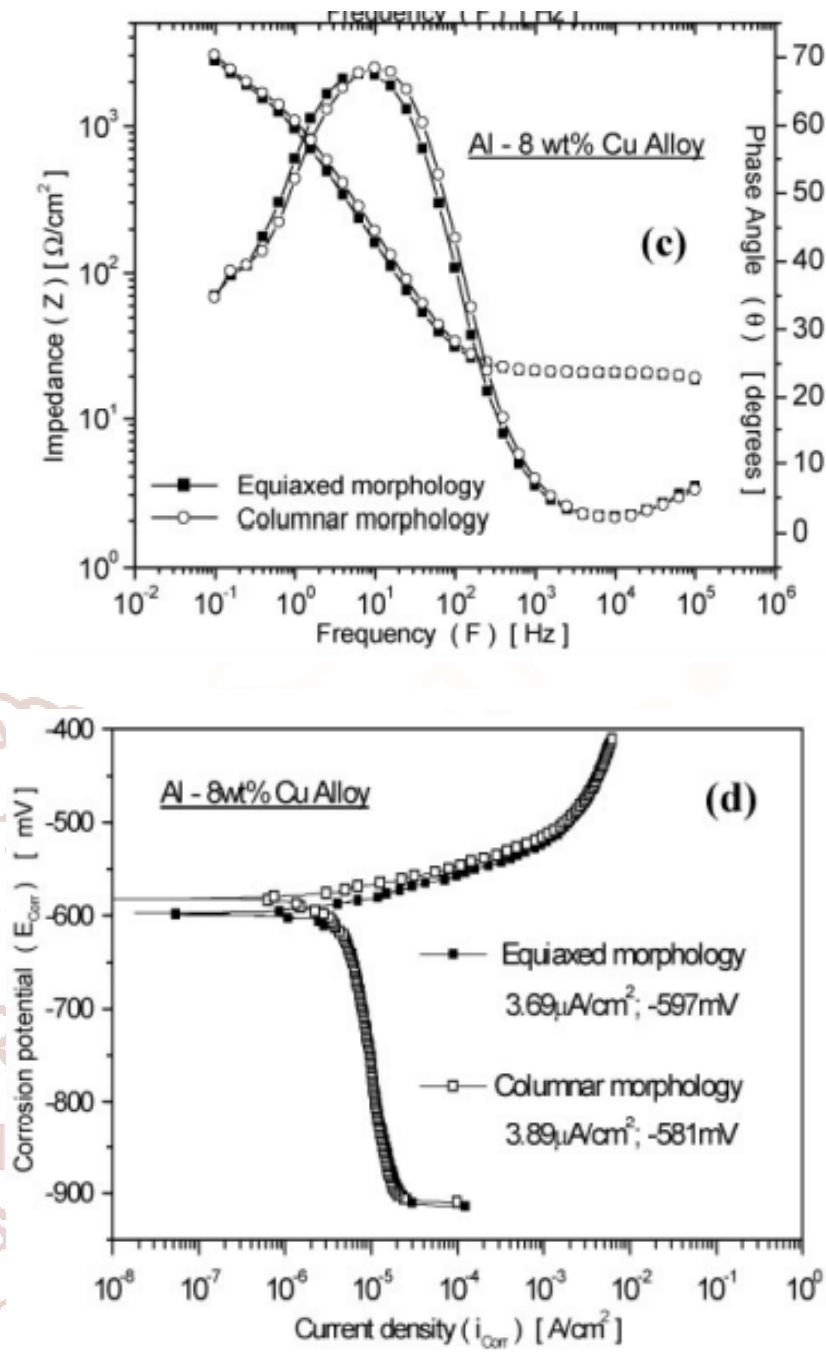

Fig 4 Comparison between experimental EIS and potentio dynamic polarization curves of a and $\mathrm{b}$ Al-5 wt- $\% \mathrm{Cu}$ alloy and $\mathrm{c}$ and $\mathrm{d} \mathrm{Al}-8 \mathrm{wt}-\% \mathrm{Cu}$ alloy on both sides of columnar to equiaxed transition

The low frequency limit (f,1 Hz) indicates the sum of Rel. and the resistance R1, which is, in a first approximation, the polarization resistance of the material surface. 11 The Bode phase or phase angle $h$ against $\log \mathrm{f}$ plot shows $\mathrm{h}$ dropping towards zero at high and low frequencies, corresponding to the resistive behavior of Rel. and the sum of Rel. plus R1. Figure 5 shows the resulting corrosion rate values ICorr as a function of secondary dendrite arm spacing 12 for $\mathrm{Al}-5 \mathrm{wt}-\% \mathrm{Cu}$ and $\mathrm{Al}-8 \mathrm{wt}-\% \mathrm{Cu}$ alloys. It can be observed that both columnar and equiaxed morphologies at the CET region for the $\mathrm{Al}-8 \mathrm{wt}-\% \mathrm{Cu}$ alloy castings exhibit lower corrosion rates than those morphologies of the Al-5 wt-\%Cu alloy. Such behavior seems to be associated with differences on micro structural features, which are known to play an important role in the corrosion resistance. Hypoeutectic $\mathrm{Al}-\mathrm{Cu}$ as cast alloys are constituted by 
an $\mathrm{Al}$ rich dendritic matrix a involved by a lamellar eutectic mixture formed by a and $\mathrm{Al} 2 \mathrm{Cu}$ lamellae. The amount of $\mathrm{A} 12 \mathrm{Cu}$ inside the interdendritic region is quite close for both alloys experimentally examined ( $\mathrm{Al}-5 \mathrm{Cu}$ and $\mathrm{Al}-8 \mathrm{Cu})$, but the secondary dendritic arm spacing is ,50\% higher for the former alloy as can be seen in Fig. 5. As a general trend, the secondary arm spacing decreases with increasing solute content of hypoeutectic alloys.

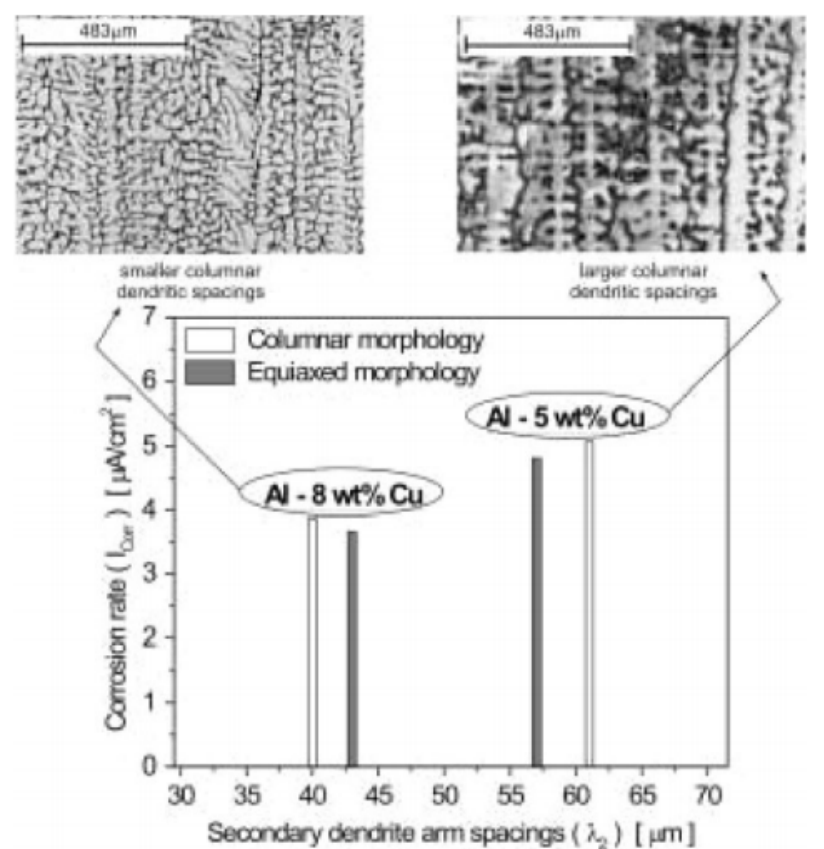

Fig 5 Corrosion rate ICorr as function of secondary dendrite arm spacing 12 for $\mathrm{Al}-5 \mathrm{wt}-\% \mathrm{Cu}$ and $\mathrm{Al}-8$ $\mathrm{wt}-\% \mathrm{Cu}$ alloys and typical microstructures

The literature reports that inter metallic particles such as $\mathrm{Al} 2 \mathrm{Cu}$ dissolves faster than the dendritic matrix when immersed in some aggressive environment.13 In the lamellar eutectic morphology, the a phase is so close to the inter metallic that it acts as a barrier to corrosion of such particles. This seems to be more effective for smaller dendritic spacing's because a more extensive distribution of the 'protective barrier' will be provided. This reasoning could explain the experimental evidence shown in Fig. 4. The frequency range $(1 \mathrm{~Hz}, \mathrm{f}, 1 \mathrm{kHz})$ is determined by the capacitance C. In the mathematical analysis of impedance diagrams, a constant phase element (CPE) was used instead of an 'ideal' capacitor to account for the deviations observed as capacities slopes and phase angle reach values lower than 21 and $90 \mathrm{u}$ respectively. The parameter $\mathrm{n}$, which is shown in Table 1, defines values that when approaching 1, the constant ZCPE is identical to an ideal capacitor, as reported in literature.11 The equivalent circuit used to fit experimental data for the different analysed alloys is shown in Fig. 6. The impedance parameters Rel., $\mathrm{R} 1, \mathrm{ZCPE}$ and $\mathrm{n}$ were evaluated using an appropriate model (ZView version 2.1b) and are presented in Table 1. It can be observed in Figs. 4 and 5 and Table 1 that both columnar and equiaxed morphologies at the CET region for the two examined $\mathrm{Al}-\mathrm{Cu}$ alloys have attained similar experimental EIS and potentio dynamic polarization results. For the $\mathrm{Al}-5 \mathrm{wt}-\% \mathrm{Cu}$ alloy, it can be seen that the current density and corrosion potential for both columnar and equiaxed morphologies around the CET region are about 5. 08 and 4. $82 \mathrm{~mA} \mathrm{~cm} 22$ and 2584 and $2620 \mathrm{mV}$ respectively. Average secondary dendrite arm spacing's 12 in both columnar and equiaxed sides at the CET region are similar, as shown in Fig. 4b. The polarisation resistance R1, capacitances values ZCPE and phase angle $n$ values are also similar for both columnar and equiaxed morphologies around the CET region. For the $\mathrm{Al}-8 \mathrm{wt}-\% \mathrm{Cu}$ alloy, the current density and corrosion potential for both columnar and equiaxed morphologies around the CET region are about 3. 89 and 3. $69 \mathrm{~mA} \mathrm{~cm} 22$ and 2581 and 2597 $\mathrm{mV}$ respectively. The mean 12 values are also very similar, as shown in Fig. 4d. In Table 1, the ZCPE, n and R1 values indicate similarity on the corrosion resistance tendency at both sides of the CET.

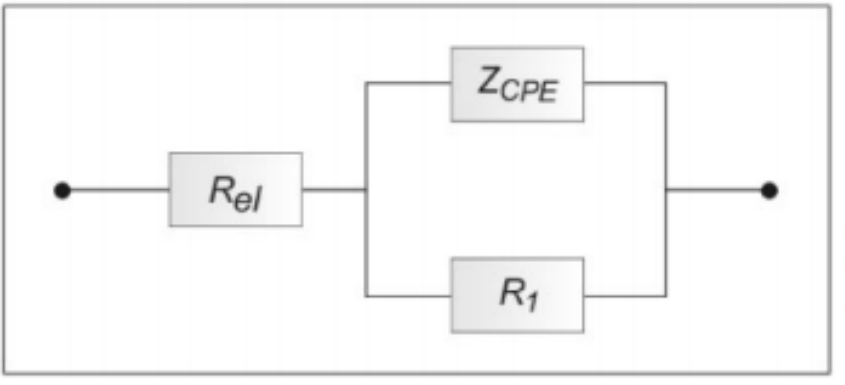

Fig 6 Equivalent circuit for modeling impedance data of examined alloys

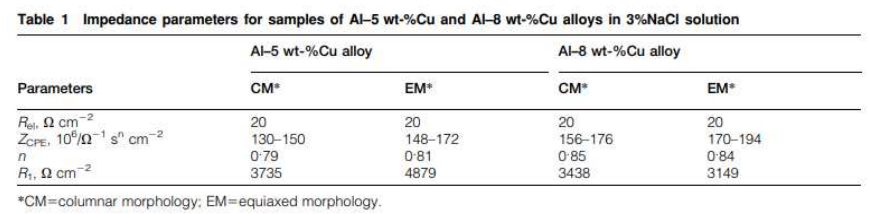

Analysing Table 1, although a variation can be observed among the impedance parameters ZCPE and R1 of both alloys, it can be seen that a same order of magnitude is attained because the observed variation can be considered irrelevant. For instance, a 103 order of magnitude is kept for all polarisation resistance values: $3.7,4.8,3.4$ and $3.2 \mathrm{kV} \mathrm{cm} 22$. Thus, the 
sole remaining factor of influence seems to be n, which indicates the phase angle. Further, the experimental fits simulated using the ZView version $2.1 \mathrm{~b}$ show that a minimum variation of $\mathrm{n}$ can provide a considerable modification on corrosion resistance tendency, with higher values indicating better corrosion behaviour, as observed for the Al-8 wt$\% \mathrm{Cu}$ alloy. The equivalent circuit results are in agreement with the current density values obtained from the potentio dynamic curves. It is important to point out that the present experimental results are limited to general corrosion. The adopted procedure to determine corrosion rates takes into account either active or non-active (nobler) surface areas. As a result, corrosion rates were determined considering the whole area.

\section{CONCLUSION}

The following conclusions can be drawn from the present experimental investigation:

1. The experimental EIS results in both Bode and Bode phase representations and Tafel polarisation results for both columnar and equiaxed sides of the CET regions have indicated a great similarity in terms of corrosion resistance for any alloy experimentally examined, despite the more extensive grain boundaries distribution typical of equiaxed structures.

2. The dendrite arm spacing seems to be the most significant structural parameter in terms of corrosion resistance because they are similar on both sides of the CET for each alloy examined, despite the dissimilarity of macrostructure.

3. The corrosion resistance has decreased with increasing alloy $\mathrm{Cu}$ content. The experimental evidence has indicated that this can be associated with smaller dendritic arm spacings.

\section{REFERENCES}

1. N. J. Petch: J. Iron Steel Inst., 1953, 174, 2531.

2. A. Lasalmonie and J. Strudel: J. Mater. Sci., 1986, $21,1837-1852$.

3. P. Donelan: Mater. Sci. Technol., 2000, 16, 261269.

4. W. R. Osó rio, C. A. Santos, J. M. V. Quaresma and A. Garcia: J. Mater. Process. Technol., 2003, 143, 703-709.

5. I. Garcia and J. J. de Damborenea: Corros. Sci., 1998, 40, 1411-1419. 